Nonlinear Processes in Geophysics, 13, 1-7, 2006

SRef-ID: 1607-7946/npg/2006-13-1

European Geosciences Union

(c) 2006 Author(s). This work is licensed

under a Creative Commons License.

\title{
Travelling ionospheric disturbance over California mid 2000
}

\author{
M. Hawarey \\ Purdue University, West Lafayette, Indiana, USA \\ Received: 12 July 2005 - Revised: 16 November 2005 - Accepted: 16 November 2005 - Published: 16 January 2006 \\ Part of Special Issue "Turbulent transport in geosciences"
}

\begin{abstract}
In this paper, the GPS data collected by more than 130 permanent GPS stations that belong to the Southern California Integrated GPS Network (SCIGN) around the launch of a Minuteman-II missile on 8 July 2000 (UTC) is processed to reveal traveling ionospheric disturbance (TID) all over the network on average $15 \mathrm{~min}$ after the launch. This TID was initially perceived to be excited by the launch itself, but this conclusion is challenged by the propagation direction. This is because this TID seems to travel towards the air force base from where the launch took place, not far away from it. This challenge is based on the assumption that TID is occurring at one single ionospheric altitude. While the nature of ionosphere supports such horizontally-guided propagation, multialtitude ionospheric pierce points are hypothesized, which would support the suggestion that detected TID is excited by the missile launch itself, despite the apparent reverse direction of propagation. The overall analysis rules out any extra-terrestrial sources like solar flares, or seismic sources like earthquakes, which confirms the conclusion of TID excitation by the launch. There is apparent coherence of the TID for about $45 \mathrm{~min}$ and the propagation speed of TID within the layer of ionosphere is calculated to be approximately equal to $1230 \mathrm{~m} / \mathrm{s}$. While the usual assumption for TID is that they occur around an altitude of $350 \mathrm{~km}$, such sound speed can only occur at much higher altitudes. Further research is recommended to accurately pinpoint the ionospheric pierce points and develop an algorithm to locate the source of TID in case it is totally unknown.
\end{abstract}

\section{Introduction}

Observations collected by dual-frequency GPS receivers have proven to be efficient in calculating absolute Total Electron Content (TEC) along the paths of incoming signals, thus enabling the mapping of the ionosphere and the

Correspondence to: M. Hawarey

(mhawarey@mars.hg.tuwien.ac.at) identification of disturbance in the density of TEC. Using this GPS-assisted methodology, traveling ionospheric disturbance (TID) excited by earthquakes (e.g. Afraimovich et al., 2001; Hawarey, 2002; Hawarey and Ayan, 2004), rocket launches (e.g. Afraimovich et al., 2000) and other sources have been reported. Researchers with no thorough background are advised to refer to Beach et al. (1997), Fitzgerald (1997), Ho et al. (1996), Matsunaga et al. (2003), Pi et al. (1997), Saito et al. (1998), Warnant and Pottiaux (2000). Although dual-frequency GPS observations provide an easy tool to calculate absolute values of TEC, this information is redundant for the mere purpose of investigating TID and any bias in the TEC values would not influence the algorithm.

In this paper the data collected by more than 130 SCIGN stations are processed to show this network's, and thus any similar dense GPS network's capability to identify and analyze TID over a big geographical region, and to determine the direction and speed of the propagation of TID.

\section{Algorithm}

For a detailed mathematical formulation, the reader is kindly referred to Hawarey and Ayan (2005). On the other hand, the redundancy of absolute TEC values for this particular application of TID detection is emphasized herewith. The only formula deemed necessary is:

$\mathrm{TEC}_{b}=\frac{\left(L_{1} f_{2}-L_{2} f_{1}\right)}{f_{1}} \frac{\lambda_{2}}{40.3} \frac{\left(f_{1}^{2} f_{2}^{2}\right)}{\left(f_{2}^{2}-f_{1}^{2}\right)}$

where the subscript $b$ indicates biased TEC values, $\mathrm{L}_{1}$ and $\mathrm{L}_{2}$ are phase observations provided in RINEX files, $\mathrm{f}_{1}$ and $\mathrm{f}_{2}$ are the famous GPS frequencies (i.e. $\mathrm{f}_{1}=1575.42 \mathrm{MHz}$ and $f_{2}=1227.60 \mathrm{MHz}$ ), and $\lambda_{2}$ is the wavelength of $f_{2}$ (i.e. $24.42 \mathrm{~cm}$ ).

In order to detect TID in the raw time series provided by Eq. (1), various filters need to be tested (i.e. low-pass, highpass, and band-pass) with various cut-off values, to make sure all types of potential TID are covered. Decision was 


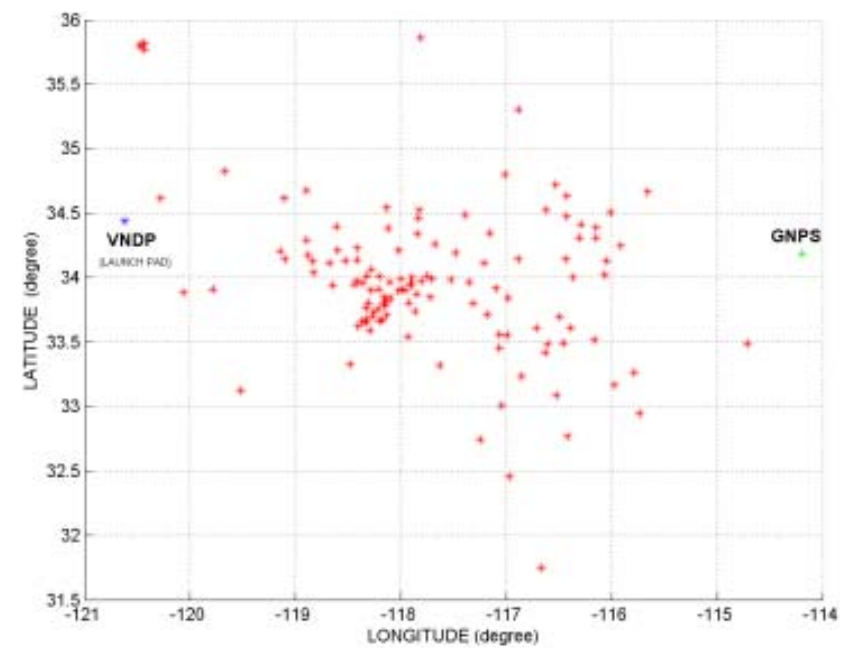

Fig. 1a. GPS stations in SCIGN used in this paper.

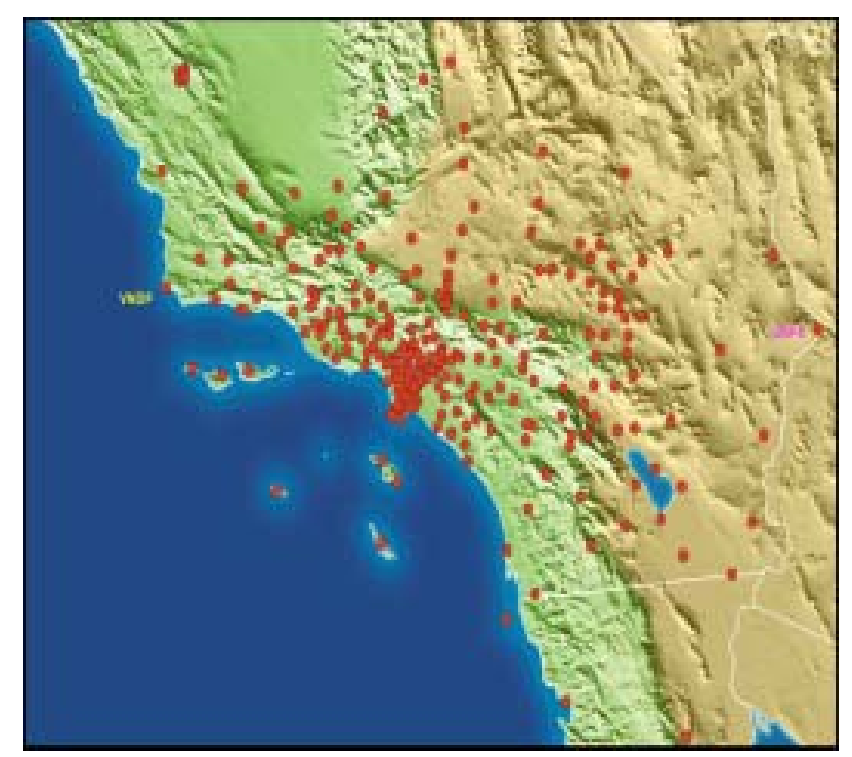

Fig. 1b. General layout of Southern California Integrated GPS Network (SCIGN) used in this paper (SOPAC, 2002).

made to use high-pass filter with 300 -s (i.e. $0.00333 \mathrm{~Hz}$ ) cutoff. In other words; all signals that have a frequency less than $0.00333 \mathrm{~Hz}$ are cancelled out, as such signals are thought to be excited by sources of no interest here like solar radiation or seismic activity. Two digital filters were tested: Chebyshev Type I and Butterworth and both proved to be efficient. Changing the sign of Eq. (1) would only result in flipped filtered TEC (FTEC) time series around the time axis (x-axis) and would not affect the analysis procedure or formulated conclusions, as this field of research has not yet reached the point of making use of the direction of the initial pulse arrival to decide on the location of the source of signal as seismologists do with initial arrivals of P-waves and S-waves to locate an earthquake's epicenter. This renders the initial pulse arrival, whether upwards or downwards with respect to the

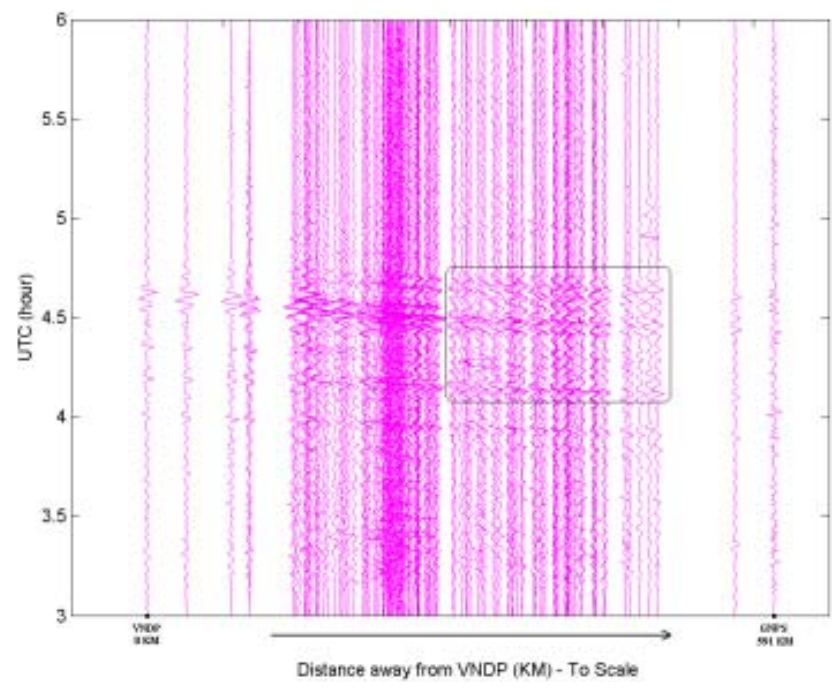

Fig. 2a. FTEC time series (electron/ $/ \mathrm{m}^{2}$ ) for satellite PRN\#19 for 135 stations on 8 July 2000.

$\mathrm{x}$-axis, immaterial. Thus, flipping the whole signal around the $\mathrm{x}$-axis does not make any difference. While if the signal were to be flipped around the y-axis, the direction perceived from Fig. 2a, as will be illustrated below, would have been reversed. Since changing the sign of Eq. (1) does not cause such reverse, the analysis becomes independent of this sign.

\section{Data processing}

The data collected by 150 GPS stations in SCIGN on 8 July 2000 was acquired from (SOPAC, 2002). Inspecting the RINEX files, 1 file had sampling interval equal to $15 \mathrm{~s}, 14$ files had the sampling interval equal to $120 \mathrm{~s}$, while 135 files had the sampling interval equal to $30 \mathrm{~s}$. In order to maintain consistency, these 15 files were ignored and the remaining 135 files were taken into account. Out of these files, $107 \mathrm{had}$ complete 360 epochs of data, 26 had 359 epochs of data, and 2 had 357 epochs of data. Since the initial motivation of the work was the missile launch that took place at 04:18 UTC, only three hours of data were kept, namely the time window of 03:00-06:00 UTC. The map of the GPS stations used is shown in Fig. 1a and the general layout of the whole SCIGN is shown in Fig. $1 b$.

The data collected from GPS satellite PRN\#19 shows very apparent TID for the whole network, while this TID was not apparent in the data collected from other satellites. It is hypothesized that the geometrical distribution of the satellites is the reason behind this. The FTEC time series for each GPS station was calculated, and a cosine bell was applied to the first $10 \%$ and last $10 \%$ of the data to taper it. This tapering (i.e. canceling out) process does not affect the end results and is done to have user friendly FTEC time series for the middle $80 \%$ portion of the data. All these FTEC time series were plotted in Fig. 2a, where they were scaled along the $\mathrm{x}$-axis according to each station's direct distance, calculated using 


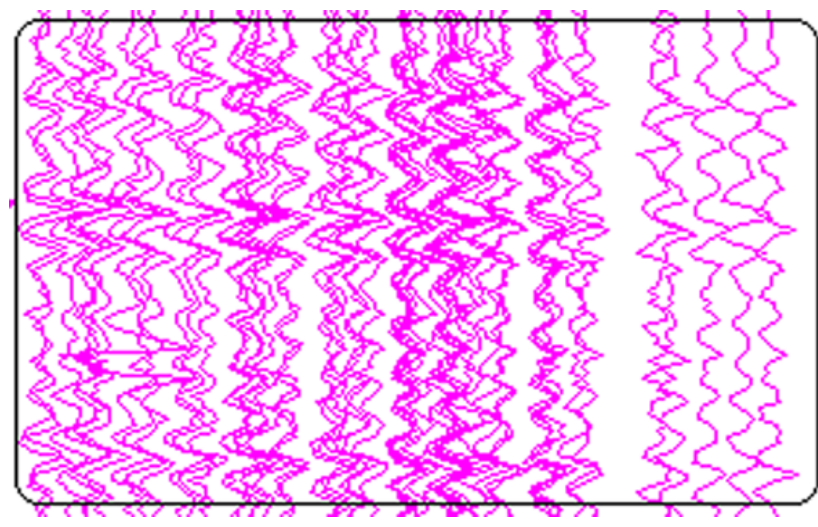

Fig. 2b. TID in Fig. 2a by fenced by rectangle, zoomed in for the sake of illustration.

XYZ coordinates, from VNDP station. This station was selected as the reference because it resides in Vandenberg Air Force Base, from where the missile was launched. Figure $2 b$ shows a zoomed-in copy of the TID fenced by rectangle in Fig. 2a, for the sake of illustration. This figure clearly shows the existence of high-frequency disturbance occurring at different instants according to the GPS signals collected at different receiver locations, confirming the fact that this disturbance is indeed traveling. When combined with Fig. 2a, the pattern of TID propagation with respect to GPS signals collected by relevant receivers can be visualized. The amplitudes of this disturbance are at least twice as big as ordinary signal amplitudes, and much more at peak values.

In order to calculate the propagation speed of the TID seen in Fig. 2a, a sharp pulse was selected and a line fit was drawn, as seen in Fig. 3. Dividing the distance between VNDP and GNPS: the station farthest away from it (i.e. $591 \mathrm{~km}$ ) by the difference in time arrivals of TID to the signal paths (i.e. $\sim 8 \mathrm{~min}$ ), which is a rough approach, results in a propagation speed approximately equal to $1230 \mathrm{~m} / \mathrm{s}$. The virtual direction of propagation is westward, as apparent from Figs. 1a and b. Doppler correction associated to ionospheric pierce points is being neglected herewith due to its anticipated relatively low effects.

Since there exist more than one wave of TID in Fig. 2a, four more series of peaks were inspected and lines were fit, in order to determine an error range of the speed. All five line fits are shown in Fig. 4, for which times ranged from $6.55 \mathrm{~min}$ to $8.72 \mathrm{~min}$. Thus, a range of propagation speed from $1130 \mathrm{~m} / \mathrm{s}$ to $1500 \mathrm{~m} / \mathrm{s}$ approximately was arrived at, for the direct distance of $591 \mathrm{~km}$. This means that the propagation speed just calculated for the maximum TID of interest (i.e. $1230 \mathrm{~m} / \mathrm{s}$ ) is within range and constitutes an acceptable value.

Selecting 15 stations out of SCIGN, the data that belong to these stations for one day earlier (i.e. 7 July 2000) and one day later (i.e. 9 July 2000) for the same time window were processed and they are shown in Figs. 5 and 7, all along Fig. 6 that shows the same analogous plot extracted from Fig. 2a for day 8 July 2000.

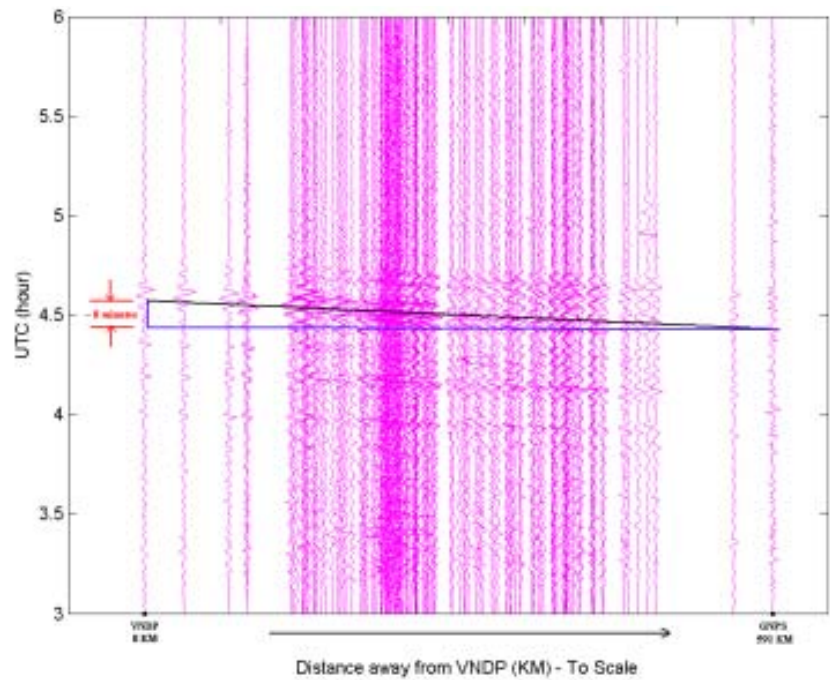

Fig. 3. Line-fit of maximum TID on FTEC time series (electron $/ \mathrm{m}^{2}$ ) for satellite PRN\#19 for the 135 stations on 8 July 2000.

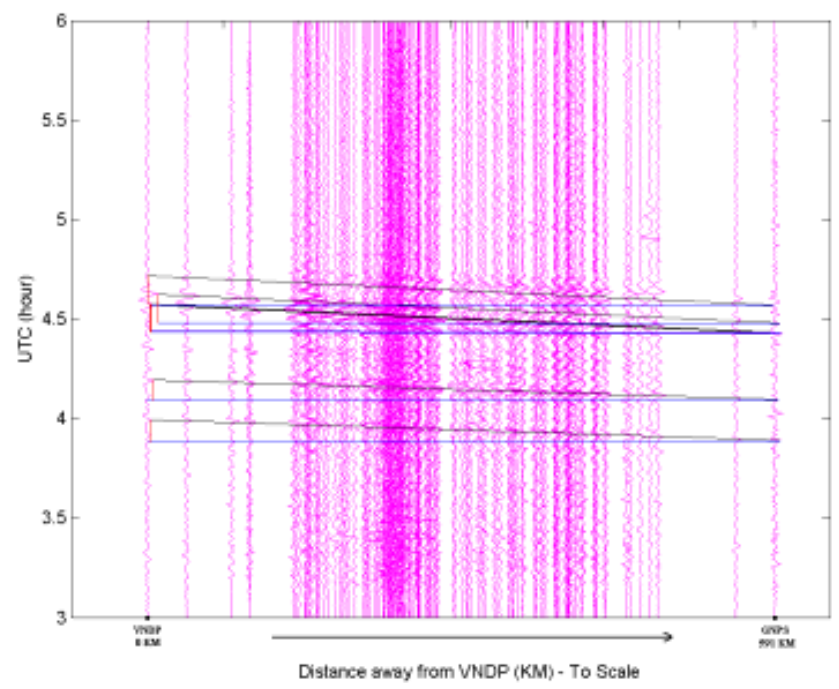

Fig. 4. Five line-fits of TID on FTEC time series (electron $/ \mathrm{m}^{2}$ ) for satellite PRN\#19 for the 135 stations on 8 July 2000.

\section{Discussion}

In spite of the fact that the usage of GPS data collected by dual-frequency GPS receivers to identify and detect TID has become a world-wide application, many of this TID are still mysterious with no obvious sources and have very different propagation speeds. Examples of these mysterious TID are the apparent ones around 04:00 UTC as seen in Fig. 2a. The focus herewith is directed towards the TID around 04:30 UTC due to the missile launch, thus TID around 04:00 are not dealt with rigorously. They may be natural TID with periods of about $600 \mathrm{~s}$ that happen during these times and seasons over California. In this paper, one of the launches of a Minuteman II missile motivated us to process the GPS data collected by nearby GPS stations in California. The 


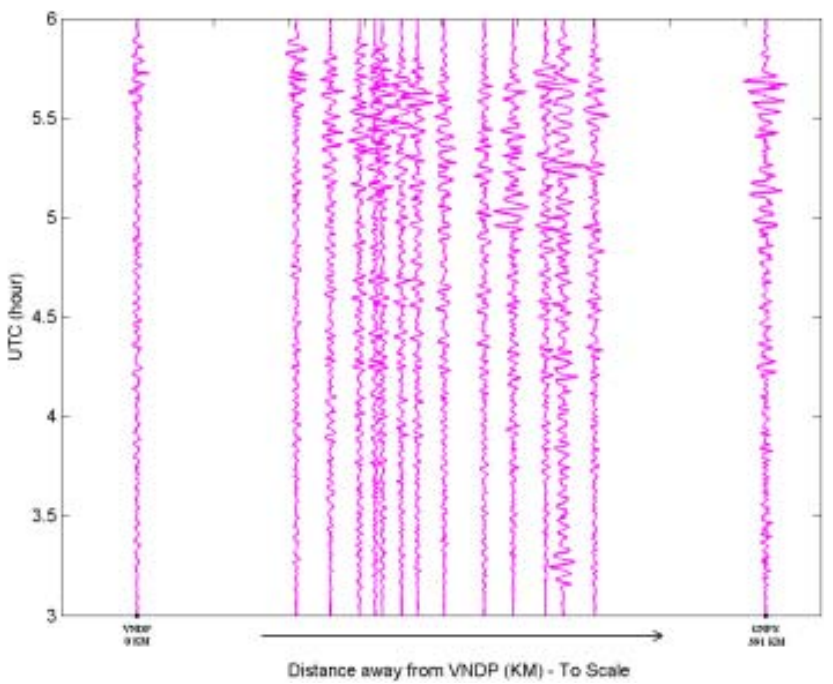

Fig. 5. FTEC time series (electron $/ \mathrm{m}^{2}$ ) for satellite PRN\#19 for 15 selected stations on 7 July 2000.

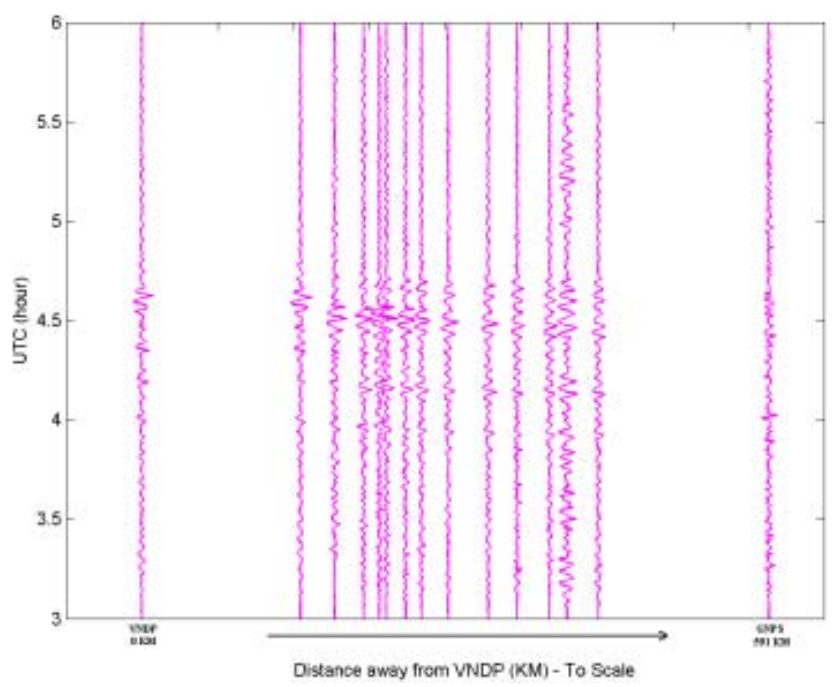

Fig. 6. FTEC time series (electron/ $/ \mathrm{m}^{2}$ ) for satellite PRN\#19 for 15 selected stations on 8 July 2000.

initial perception indicated the detection of TID excited by this launch, with TID showing peak values around $15 \mathrm{~min}$ after the launch, as the missile launch took place at 04:18 UTC and the initial strikes of pulse (the series of peaks), as seen in Fig. 2a, occured from 04:26 UTC thru 04:35 UTC. After inspection of the density of peaks, $04: 33$ o'clock was taken as an average; $15 \mathrm{~min}$ after 04:18 UTC. This would indicate a propagation speed from the launch pad towards the IPs (Ionospheric Points: points of intersection between GPS signal rays and ionospheric layer with maximum electron density, often called ionospheric pierce points) equivalent to sound speeds. Taking $300 \mathrm{~km}$ as the approximate altitude at which IPs occurred, an average value of propagation speed of TID from the launch pad towards IPs was calculated approximately equal to $334 \mathrm{~m} / \mathrm{s}$. While other altitude values

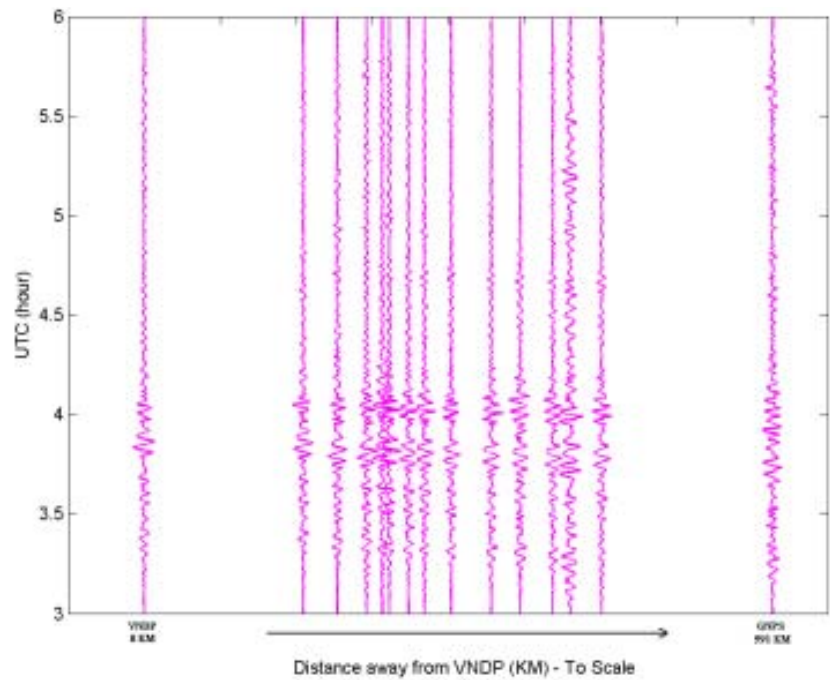

Fig. 7. FTEC time series (electron $/ \mathrm{m}^{2}$ ) for satellite PRN\#19 for 15 selected stations on 9 July 2000.

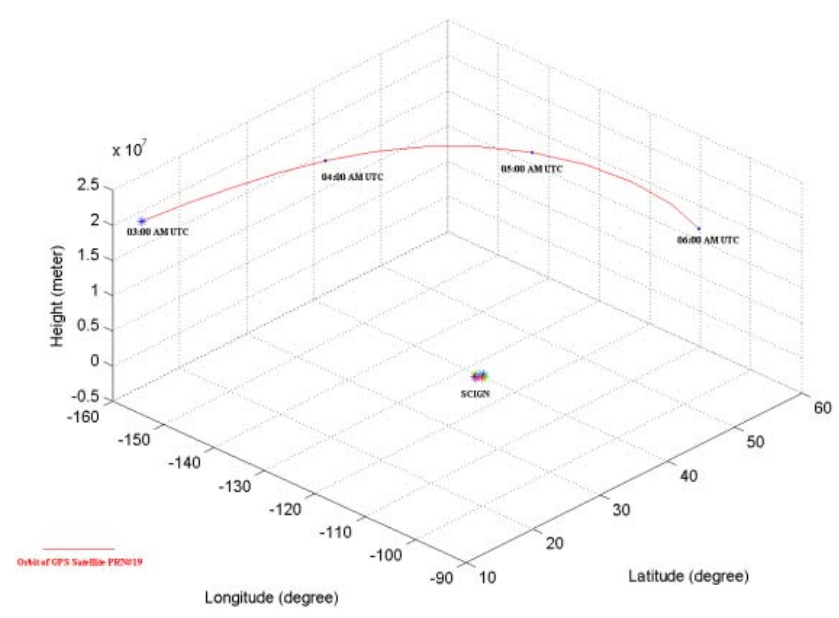

Fig. 8. Orbit of satellite PRN\#19 over SCIGN on 8 July 2000.

could have been selected (Hawarey et al., 2005), this value is deemed appropriate to get a good impression and idea of how the disturbance is traveling. Processing few stations' data rendered the acquired propagation speed sensible. However, as the results have been acquired for 135 stations, the virtual VNDPward propagation direction suggests that the detected TID perhaps have not been excited by the launch. The propagation speed calculated from Fig. 3 (i.e. 1230 m/s) suggests a higher value than the one calculated assuming excitation by the launch (i.e. $334 \mathrm{~m} / \mathrm{s}$ ). On the other hand, it must be kept in mind that the value of $1230 \mathrm{~m} / \mathrm{s}$ is an approximation, in the presence of other waves as seen in Fig. 4. Also, the $1230 \mathrm{~m} / \mathrm{s}$ is a propagation speed within the ionosphere itself, while $334 \mathrm{~m} / \mathrm{s}$ is a propagation speed within the lower atmospheric layers towards the ionosphere. This point deserves further inspection, thus further research is recommended.

It should be noticed that despite the calculation of propagation speed from Fig. 3 being approximate; the position of 


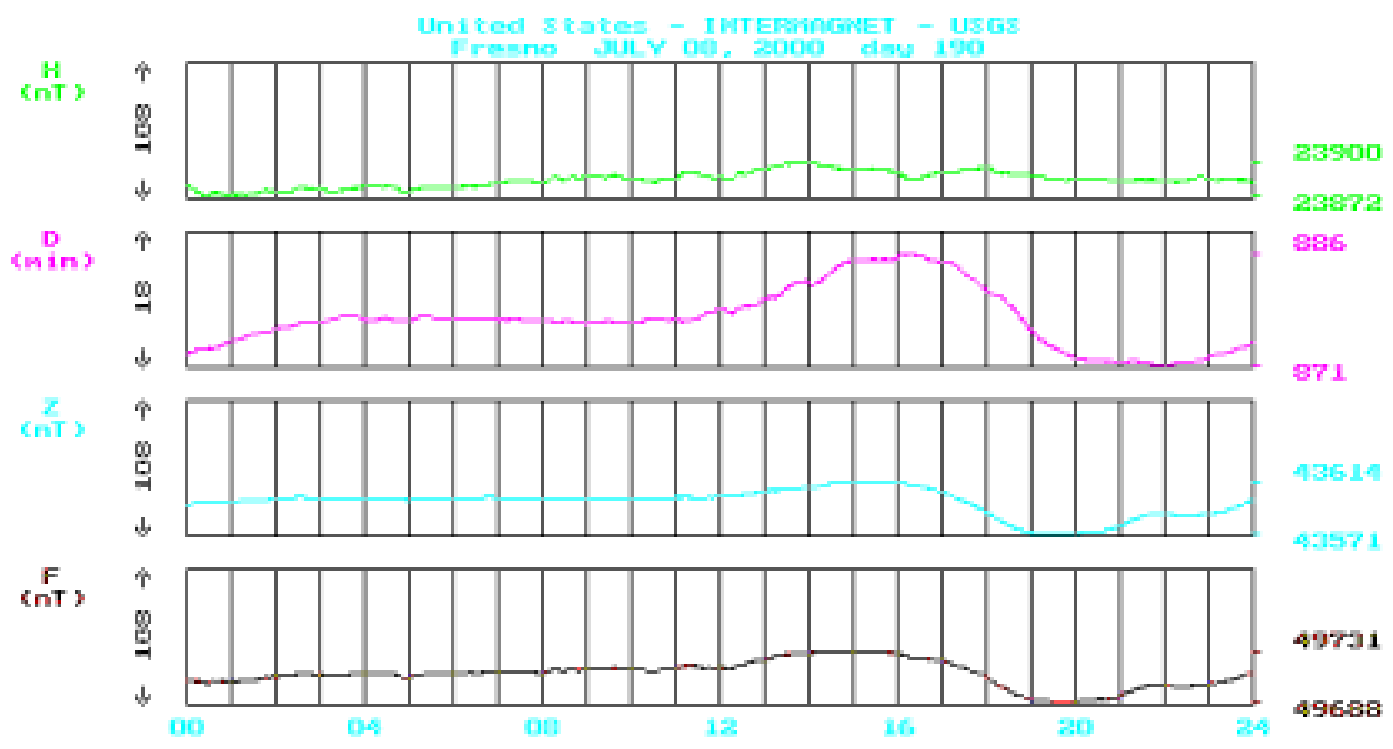

Fig. 9. Definitive Geomagnetic Data from Observatory Fresno on 8 July 2000, where F is the total density and D, H, and Z are the one-minute, hourly, and daily mean values of the vector components.

PRN\#19 provided by IGS (2003) as seen in Fig. 8 makes it acceptable. That's to say: the position of PRN\#19 around 04:35 UTC makes the separation between the IPs of VNDP and GNPS almost the same as the $591 \mathrm{~km}$ distance between VNDP and GNPS, which renders the calculated propagation speed of the TID of $1230 \mathrm{~m} / \mathrm{s}$ acceptable.

Extra-terrestrial sources like solar flares have been ruled out by inspecting the 1-min Definitive Geomagnetic data of the Fresno Observatory in California provided by (INTERMAGNET, 2003), which is seen in Fig. 9. Also, no noteworthy seismic activity of earthquakes was reported by the (USGS, 2003) for the time window of concern here, and seismogram data gotten from (SCEC, 2003) for many seismometers in the region confirmed that.

A quick look at the sound speed profile provided in Garcés et al. (1998) and seen in Fig. 10 reveals by hypothetical extrapolation that the altitude at which these ionospheric disturbance are traveling is at least $400 \mathrm{~km}$ and may be much higher. This is kept in mind when reaching the conclusions in the following chapter and hypothesizing that TID may indeed be occurring at varying altitudes, keeping the door open for future intensive research and observations of the ionosphere by state-of-the-art probes.

It is thought that the nature of the identified TID is different from those presented in other publications due to the propagation speed (i.e. 100-150 m/s in Garcés et al., 1998, and $500 \mathrm{~m} / \mathrm{s}$ in Saito et al., 2001) and because using filtering algorithms similar to those presented in these papers did not result in similar TID to those presented in them. For example, applying 10-min to 3-min band-pass filter did not succeed in removing the low-frequency fluctuation in FTEC that is caused by daily solar activity as in other case studies. The band is defined in descending order (from 10 to 3 ) because it is applied in frequency domain, thus it is reversed when expressed in time domain.
While the FTEC time series of 7 July 2000 show incoherent fluctuations of high amplitude towards the end of the time window and multiple low-amplitude coherent ones at many instants before that, the FTEC time series of 9 July 2000 show two discrete low-amplitude coherent TID traveling across the network over about 30 -min period. The incoherence in Fig. 5 makes it difficult to detect any propagation, while the coherent signals in Fig. 7 do not seem to propagate as in Fig. 6 (i.e. 8 July 2005). The signals on both Figs. 5 and 7 have lower amplitude than those on Fig. 6, with higher periods of about $600 \mathrm{~s}$, showing apparent westward TID signatures. They may very well be associated with TID happening during such times and seasons over California. When combining all these factors with the fact that TID on Fig. 6 appeared minutes after the missile launch, it becomes apparent why the whole concentration in this paper has been over 7 July 2005. The question remains open regarding the origin of TID that cannot be associated with the missile launch and it deserves further investigation.

\section{Conclusions}

GPS technology provides an easy tool not only to map the ionosphere and produce global IONEX data, but to map traveling disturbance that occur in the electron density of the ionosphere over hundreds of kilometers. Because the majority of permanent GPS stations collect data at 30-s intervals due to efficiency and storage reasons, there is temporal limitation on the detective work being done. However, GPS stations with 1-s sampling intervals are starting to appear and they are promising.

The data does suggest that the detected TID have occurred on average $15 \mathrm{~min}$ after the Minuteman II missile launch. The calculated propagation speed does seem to be 


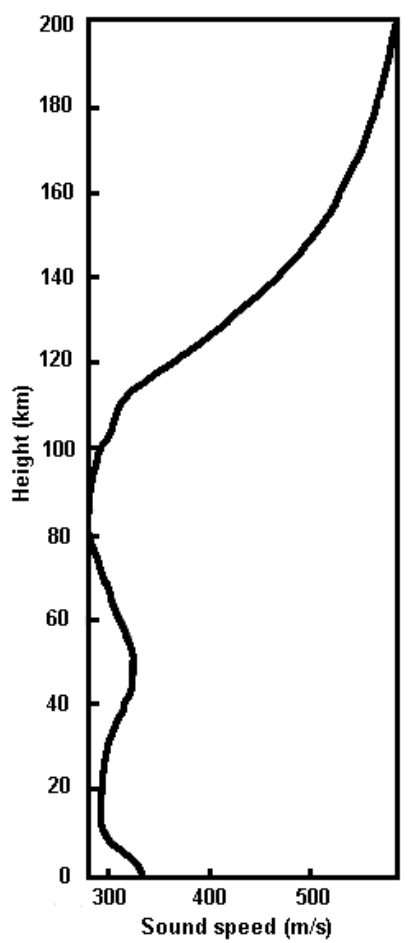

Fig. 10. Sound speed profile up to $200 \mathrm{~km}$ altitude in the atmosphere (Garcés et al., 1998).

consistent with the overall phenomena, too. The major challenge against such conclusion of launch detection would rise from the apparent westward direction of propagation, which is somehow similar to Afraimovich et al. (2003), where it was stated that the TID that occurred after high-altitude explosion had a propagation direction not supporting the hypothesis that the explosion had excited them. Such a challenge is based on the assumption that the entire ionospheric disturbance took place at the same altitude. While the nature of the layer of ionosphere may support such horizontallyguided propagation, it certainly does not exclude the varyingaltitude propagation, thus the challenge is arguable. Actually, if it is hypothesized to have high-altitude pierce points near the launch pad and low-altitude pierce points faraway from it, in the absence of tangible evidence that proves the impossibility of this hypothesis, then westward direction would be acceptable for TID excited by the missile launch. In the absence of any other source that may have excited the TID, like solar flares or seismic activity, the conclusion of missile launch detection is strengthened. This leads us to conclude, at the same time, the potential capability of pinpointing the location of the source (i.e. launch pad in this case) using GPS data. Further research and full geophysical analysis is deemed necessary to try to decide on the exact pierce points' locations and to develop an algorithm to pinpoint the source, in case it is unknown. Such research would show if there are relationships among TID occurring after the missile launch and those appearing one day before and one day after, which are thought in this paper to be associated with seasonal TID over California during such times.
The varying values of propagation speeds reported in the literature and in this paper indicate the existence of different types of disturbances traveling across the ionosphere with different speeds and at different heights. Further extensive research is recommended to classify the different types of TID and to develop a standard documentation format for them (e.g. TIDEX).

Acknowledgements. The author would like to thank everyone assisting in having the websites of Scripps Orbit and Permanent Array Center (SOPAC), International GPS Service (IGS), United States Geological Survey (USGS) and Southern California Earthquake Data Center (SCEC) fully functional and available to the usage of everyone world-wide, free of charge. Also, INTERMAGNET is acknowledged for providing the complete sets of Definitive Geomagnetic Data, free of charge.

Edited by: J. M. Redondo

Reviewed by: H. Schuh and two other referees

\section{References}

Afraimovich, E. L., Kosogorov, E. A., Palamarchouk, K. S., Perevalova, N. P., and Plotnikov, A. V.: The use of GPS arrays in detecting the ionospheric response during rocket launchings, Earth, Planets, and Space, 52, N11, 1061-1066, 2000.

Afraimovich, E. L., Perevalova, N. P., Plotnikov, A. V. and Uralov, A. M.: The shock-acoustic waves generated by the earthquakes, Ann. Geophys., 19, 395-409, 2001,

SRef-ID: 1432-0576/ag/2001-19-395.

Afraimovich, E. L., Voyeikov, S. V., Lesyuta, O. S., Perevalova, N. P., and Nagorsky, P. M.: The traveling ionospheric disturbance conceivably initiated by a high altitude explosion during the testing of the US anti-missile system on July 15, 2001, SolarTerrestrial Physics, 3, Institute of Solar-Terrestrial Physics SB RAS, Irkutsk, 73-79, 2003.

Beach, T. L., Kelley, M. C., and Kintner, P. M.: Total electron content variations due to nonclassical traveling ionospheric disturbances: Theory and Global Positioning System observations, J. Geophys. Res., 102, 7279-7292, 1997.

Fitzgerald, T. J.: Observations of total electron content perturbations on GPS signals caused by a ground level explosion, J. Atmos. Terr. Phys., 59, 829-834, 1997.

Garcés, M. A., Hansen, R. A., and Lindquist, K. G.: Traveltimes for infrasonic waves propagating in a stratified atmosphere, Geophys. J. Int., 135(1), 255, doi:10.1046/j.1365246X.1998.00618.x, 1998.

Hawarey, M.: GPS Detection of Izmit Earthquake and Shape Model of already GPS-Detected Space Shuttle Launch in 1993, Weikko A. Heiskanen Symposium in Geodesy, The Ohio State University, 1-4 October 2002.

Hawarey, M. and Ayan, T.: GPS detection of ionospheric perturbations excited by space shuttle ascent, earthquake, and missile launch, itudergisi, Ser. d, 3, No. 2-3-4-5, ISSN 1303-703X, 4556, 2004.

Hawarey, M. and Ayan, T.: GPS Detection of Minuteman II Launch and Positioning of Launch Site, J. Surveying Eng., 131, 3, 78-86, doi:10.1061/(ASCE)0733-9453(2005)131:3(78), 2005.

Hawarey, M., Hobiger, T., and Schuh, H.: Effects of the 2nd order ionospheric terms on VLBI measurements, Geophys. Res. Lett., 32(11), L11304, doi:10.1029/2005GL022729, 2005. 
Ho, C. M., Mannucci, A. J., Lindqwister, U. J., Pi, X., and Tsurutani, B. T.: Global ionosphere perturbations monitored by the worldwide GPS network, Geophys. Res. Lett., 23(22), 32193222, 1996.

INTERMAGNET: International Real-time Magnetic Observatory Network, CD of Definitive Geomagnetic Data of 2000, France, 2003.

IGS: International GPS Service's website: http://igscb.jpl.nasa.gov/ index.html, 2003.

Matsunaga, K., Hoshinoo, K., and Igarashi, K.: Observations of Ionospheric Scintillation on GPS Signals in Japan, Navigation, 50, 1, 2003.

Pi, X., Mannucci, A. J., Lindqwister, U. J., and Ho, C. M.: Monitoring of global ionospheric irregularities using the worldwide GPS network, Geophys. Res. Lett., 24(18), 2283-2286, 1997.

Saito, A., Fukao, S., and Miyazaki, S.: High resolution mapping of TEC perturbations with the GSI GPS network over Japan, Geophys. Res. Lett., 25(16), 3079-3082, 1998.
Saito, A., Nishimura, M., Yamamoto, M., Kubota, M., Shiokawa, K., Otsuka,Y., Tsugawa, T., Fukao, S., Ogawa, T., Ishii, M., Sakanoi, T., and Miyazaki, S.: Traveling ionospheric disturbances detected in the FRONT campaign, Geophys. Res. Lett., 28(4), 689-692, 2001.

SCEC: Southern California Earthquake Data Center's website: http: //www.data.scec.org, 2003.

SOPAC: Scripps Orbit and Permanent Array Center's website: http: //sopac.ucsd.edu, 2002.

USGS: United States Geological Survey's website, http://www. usgs.gov, 2003.

Warnant R. and Pottiaux, E.: The increase of the ionospheric activity as measured by GPS, Earth Planets Space, 52, 1055-1060, 2000 . 